\title{
Giant Ganglion Cyst Arising from Iliac Wing, an Atypical Site
}

\author{
Junya Oshima ${ }^{1}$ Yukiko Imai ${ }^{1}$ Kaoru Sasaki ${ }^{1} \quad$ Mitsuru Sekido ${ }^{1}$
}

${ }^{1}$ Department of Plastic, Reconstructive, and Hand Surgery, University of Tsukuba, Tsukuba, Ibaraki, Japan

Indian J Plast Surg 2021;54:244-245.

\section{Introduction}

Ganglion cysts are benign cystic lesions, typically measuring 1 to $2 \mathrm{~cm}$ in size, which are often encountered and commonly located around the joints of the wrist and fingers. ${ }^{1,2}$ Among the rarer locations, ganglion cysts arising from the iliac wing are extremely scarce.

The patient, a 61-year-old woman, had become aware of a swelling on the waist 10 years prior. At her first consultation, a $15 \times 18 \mathrm{~cm}$-sized subcutaneous mass was found on the right iliac crest ( - Fig. 1). On MRI, the inside of the lesion was uniform, with low brightness in the T1-weighted image and high brightness in the T2-weighted image. The lesion margin was mostly smooth and clear, but the border proximal to the iliac bone was undefined ( - Fig. 2). Needle aspiration showed a viscous liquid with no apparent malignant cells. Based on the above findings, a diagnosis of ganglion cyst was made. Surgery was performed under general anesthesia to improve the feeling of oppression and appearance.
Address for correspondence Junya Oshima, MD, Department of plastic, reconstructive, and hand surgery, University of Tsukuba, 1-1-1 Tennodai, Tsukuba, Ibaraki 305-8577, Japan (e-mail: ooshima-tuk@umin.ac.jp).

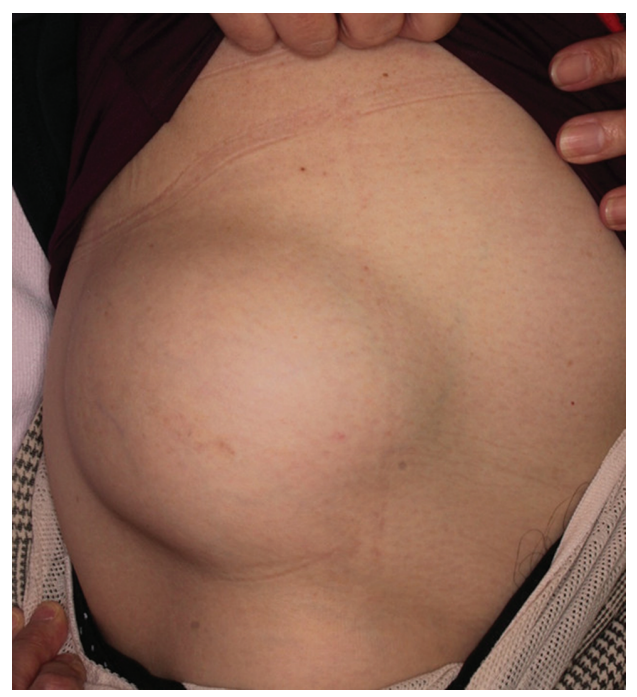

Fig. 1 Findings at the first visit: A $15 \times 18 \mathrm{~cm}$-sized subcutaneous mass was found in the right iliac/crest.

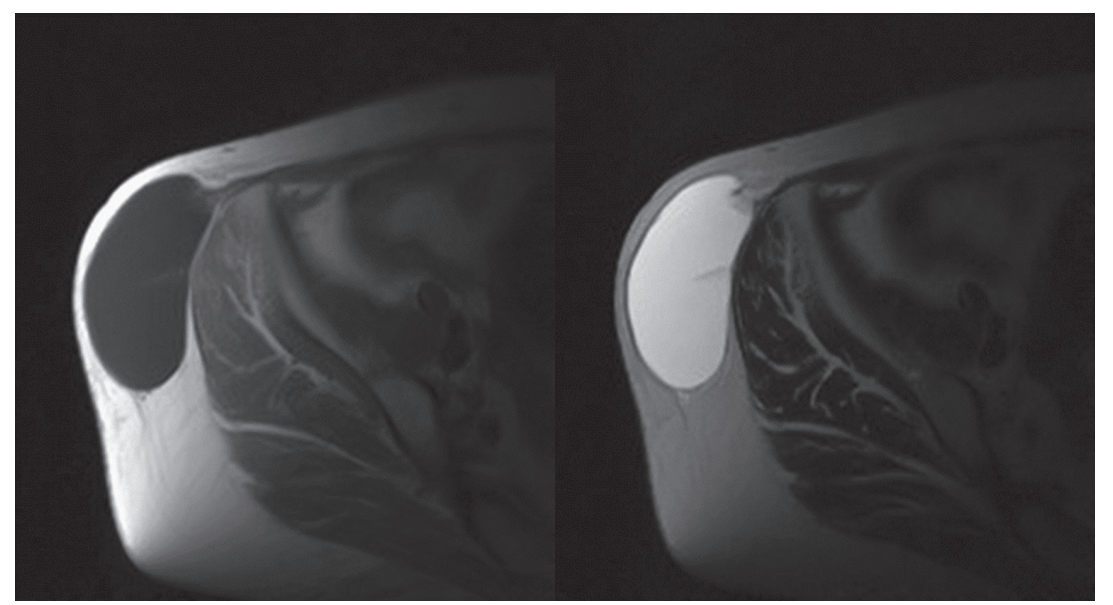

Fig. 2 MRI findings: The inside of the lesion was uniform, with low brightness in the T1-weighted image (left) and high brightness in the T2-weighted image (right).

published online March 10, 2021
DOI https://doi.org/

$10.1055 / \mathrm{s}-0041-1725225$ ISSN 0970-0358.
(C) 2021. Association of Plastic Surgeons of India.

This is an open access article published by Thieme under the terms of the Creative Commons Attribution-NonDerivative-NonCommercial-License, permitting copying and reproduction so long as the original work is given appropriate credit. Contents may not be used for commercial purposes, or adapted, remixed, transformed or built upon. (https://creativecommons.org/licenses/by-nc-nd/4.0/).

Thieme Medical and Scientific Publishers Pvt. Ltd. A-12, 2nd Floor, Sector 2, Noida-201301 UP, India 


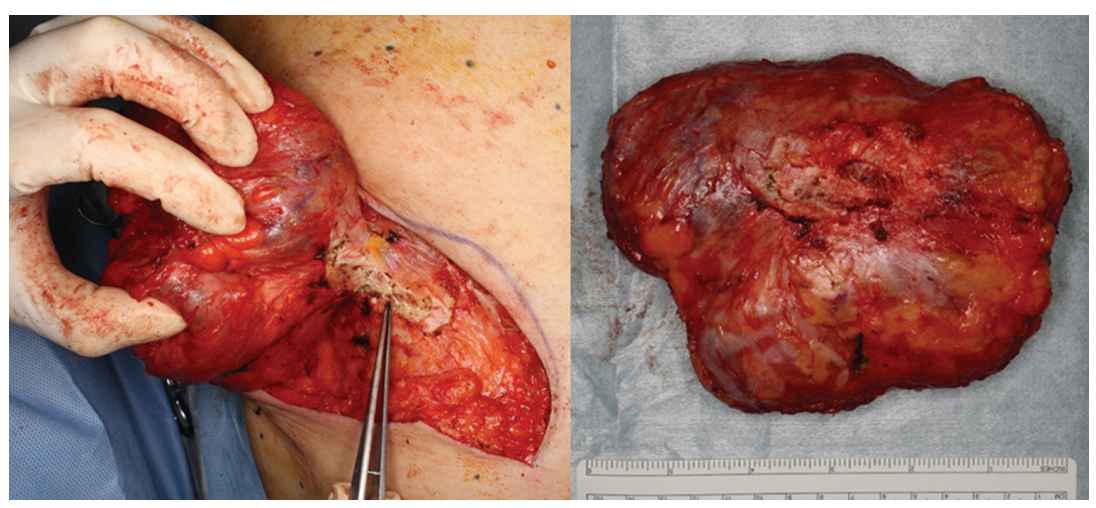

Fig. 3 Intraoperative findings: (left) There was a strong adhesion at the iliac crest on the deep surface of the cyst. (right) Resected cyst. The site of adhesion was excised, including the external oblique fascia and tendon tissue of the external oblique muscle attachment, resulting in complete extraction of the cyst without any leakage.

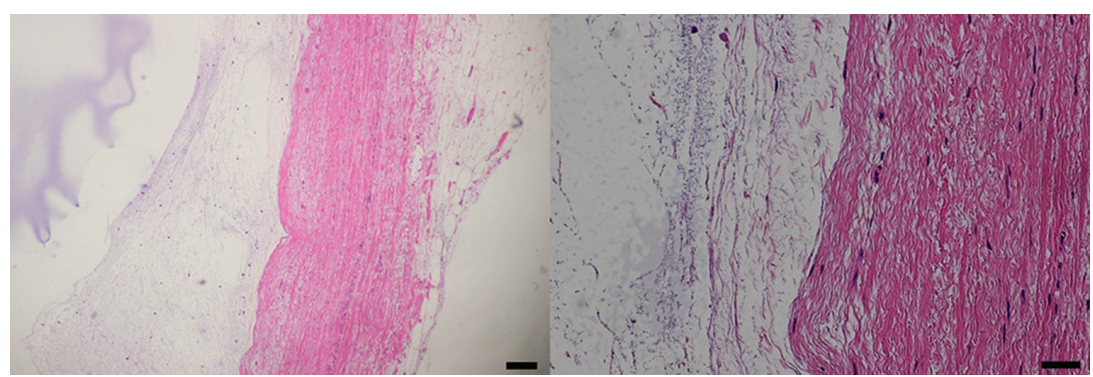

Fig. 4 Pathological findings (hematoxylin and eosin stain): (left) The lesion was a unilocular cyst containing mucus. The cyst wall consisted of edematous connective tissue (scale bar: $200 \mu \mathrm{m}$ ). (right) No lining epithelium was found (scale bar: $100 \mu \mathrm{m}$ ).

Although the cyst could largely be easily peeled off without adhesion to the surroundings, there was a strong adhesion at the iliac crest on the deep bottom surface of the cyst. The site of adhesion was excised, including the external oblique fascia and tendon tissue of the external oblique muscle attachment ( - Fig. 3). The cyst did not show deep continuity to the surrounding tissues or hip joint. Pathologically, the lesion was a unilocular cyst containing mucus. The cyst wall consisted of edematous connective tissue with no epithelium lining, and the diagnosis was ganglion cyst ( - Fig. 4 ). The ganglion cyst was thought to have originated from the connective tissue of the iliac crest, because it had no involvement in the joint. There was no recurrence of the cyst 18 months after surgery.

There was only one previous report of ganglion arising from the iliac wing without involvement with the hip joint, but it was small cyst $(\sim 2 \mathrm{~cm})$ under the periosteum. ${ }^{3}$ The current case had no continuity with the joint cavity, tendon sheath, or periosteum. Typically, ganglion cysts are classified as intra-articular, extra-articular, intraosseous, and periosteal, depending on the site of origin. ${ }^{4}$ Lesions without continuity such as this case are difficult to classify. Considering the developmental mechanism and treatment method, this case has more commonality with periosteal ganglion than the other types. It has been pointed out that periosteal ganglion cysts are associated with trauma history. ${ }^{5}$ This case had no apparent preceding trauma but may be associated with repetitive micromechanical stimulation due to the protruding iliac wings. In periosteal ganglion, no consensus has been obtained on the optimal extent of resection. At least the connective tissue where the tumor is in strong contact is suggested to be excised. In our case, fascia, and tendon tissue of the muscle attachment, which were strongly adhered to the cyst, was removed. There was no apparent bone or periosteum exposure. Because it is a benign disease, bone resection and extended resection were not performed in consideration of invasiveness.

\section{Disclosure}

No financial disclosure.

\section{Conflicts of Interest}

None declared.

\section{Acknowledgments}

We would like to thank Dr. Bryan J. Mathis (Medical English Communications Center) for language revision of this manuscript.

\section{Reference}

1 Head L, Gencarelli JR, Allen M, Boyd KU. Wrist ganglion treatment: systematic review and meta-analysis. J Hand Surg Am 2015;40(3):546-53.e8

2 Angelides AC, Wallace PF. The dorsal ganglion of the wrist: its pathogenesis, gross and microscopic anatomy, and surgical treatment. J Hand Surg Am 1976;1(3):228-235

3 Nadas S, Landry M, Duvoisin B, Richoz B, Maire P. Subperiosteal ganglionic cyst of the iliac wing. Skeletal Radiol 1995; 24(7):541-542

4 Perdikakis E, Skiadas V. MRI characteristics of cysts and "cystlike" lesions in and around the knee: what the radiologist needs to know. Insights Imaging 2013;4(3):257-272

5 Abdelwahab IF, Hermann G, Kenan S, Klein MJ. Periosteal ganglia: current concept review. Can Assoc Radiol J 1998; 49(6):381-389 